Vol.8, Issue 4, pp.95-102, April 2020

Published by ECRTD- UK

Print ISSN: ISSN 2054-6351: Online ISSN: ISSN 2054-636X

\title{
AM I RIGHT? THE EFFECTS OF FEEDBACK ON THE PERFORMANCE IN A MENTAL-ROTATION TEST IN CHILDREN
}

\author{
Martina Rahe and Claudia Quaiser-Pohl \\ University of Koblenz-Landau, Universitaetsstrasse 1, 56070 Koblenz, Germany \\ Email: rahe@uni-koblenz.de
}

\begin{abstract}
Gender differences in paper-and-pencil mental-rotation tests are usually larger than in chronometric versions. Different task characteristics such as time constraints, number of items, or feedback could partly be responsible for these varying gender differences. In the present study, 40 male and 59 female fourth-grade children participated in a chronometric mental-rotation test. In the feedback condition, children got individual item-wise feedback while children in the nonfeedback condition got no feedback about their performance. For reaction time, boys outperformed girls and overall, children in the feedback condition reacted faster than children who got no feedback. On a closer look, only boys but not girls benefited from the feedback and gender differences in favour of boys appeared only in the feedback condition. Results indicate that feedback encouraged boys to solve the items faster while it made no difference for girls. For mental-rotation as a spatial task that is perceived as more male-stereotyped, boys could have been more confident in their own ability. The feedback could then have enhanced this confidence so that boys felt sure enough to react faster. It seemed that girls were not able to use the feedback to reduce their own uncertainty.
\end{abstract}

KEYWORDS: mental rotation, gender differences, feedback

\section{INTRODUCTION}

Mental rotation is the spatial ability to rotate two- or three-dimensional objects in one's mind (Linn \& Petersen, 1985). In most mental-rotation tests, participants have to decide as quickly and as accurately as possible whether one object is an identical and rotated version of another object or whether it is structurally different or a mirrored version (Voyer, Voyer, \& Bryden, 1995). Mentalrotation tests are administered either on a computer screen (Shepard \& Metzler, 1971) or as a paperand-pencil version (MRT) (Vandenberg \& Kuse, 1978). Both versions of the test differ in some task characteristics. In most computerized test, there are two objects that have to be compared, individual feedback is given after each item, a higher number of items has to be solved, and no time limit is given for the solution (Shepard \& Metzler, 1971). In the MRT, four figures have to be compared to one target figure and a time limit is often given for solving the items (Vandenberg \& Kuse, 1978).

\section{Gender Differences in Mental-Rotation Tests}

In mental-rotation tests, gender differences consistently appear in favour of males (Linn \& Petersen, 1985, Voyer et al., 1995). A meta-analysis comparing both versions of the test found smaller gender differences for the computerized test than for the MRT (Voyer et al., 1995). Analysing the comparability of both test, two studies found similar effects of gender in undergraduate students (Voyer et al., 2006) and second and fourth-grade children (Quaiser-Pohl, Neuburger, Heil, Jansen, \& Schmelter, 2014). 
Some of the task characteristics of the tests mentioned above could partly be responsible for these varying gender differences. Results of previous research found that gender differences were larger when the items of the MRT had to be solved with a time limit compared to a condition without time constraints (Voyer, 2011). Furthermore, more males than females attempted to solve the last problems in a test (Peters, 2005) which indicates that females needed more time for the solution. Besides time constraints, the individual item-wise feedback in the computerized test could have different effects on the test performance of males and females.

\section{Effects of Feedback}

Feedback is information about participants' performance provided by e.g. a teacher, parent, or computer program (Hattie \& Timperley, 2007). Effects of feedback on learning or on the performance in a cognitive ability test are mostly positive (Bangert-Drowns, Kulik, Kulik, \& Morgan, 1991; Azevedo \& Bernhard, 1995; van der Kleij, Feskens, \& Eggen, 2015). Feedback can lead to more effort, motivation, and engagement and cue searching can be increased (Hattie \& Timperley, 2007). Feedback about the task can result in "the development of more effective and efficient strategies for processing and understanding the material" (Hattie \& Timperley, 2007). Feedback at the process can lead to higher confidence or more effort (Hattie \& Timperley, 2007). Initially gender differences in self-efficacy in a mathematical task disappeared after performance feedback was provided (Schunk \& Lilly, 1984). Girls reported lower levels of self-efficacy than boys only in the pretest before the novel task but not after their problem-solving and receiving feedback on their performance.

Feedback after a response given with high confidence is more effective than feedback after a response with low confidence (Kulhavy, Yekovich, \& Dyer, 1976). Contrary to these results, Butler, Karpicke, and Roediger (2008) found that in the feedback condition, participants with low confidence maintained their initially correct answers in a second test but often changed their response to an incorrect answer when they got no feedback. In a decision making task, participants in the feedback condition shifted their speed-accuracy balance into the speed direction indicating that feedback encouraged subjects to make their decision faster at the expense of decreasing accuracy (Starns \& Ratcliff, 2010).

Feedback can also lead to higher motivation (Hattie \& Timperley, 2007). Katz, Assor, KanatMaymon, and Bereby-Meyer (2006) asked children about their interest in logic, puzzles, and thinking games and then let them work on logic questions. After either positive or no feedback was given randomly to the participants, they filled out a questionnaire about their intrinsic motivation. A main effect of interest was found indicating that children who reported higher interest also scored higher in intrinsic motivation. In children with moderate interest, feedback had different effects on boys and girls: positive feedback resulted in higher intrinsic motivation in boys while girls reported lower scores of intrinsic motivation when they received positive feedback. The authors suggested that by girls, positive feedback was perceived as an attempt to control them (Katz et al., 2006).

Furthermore, feedback can lead to higher confidence (Hattie \& Timperley, 2007). Earley, Northcraft, Lee, and Lituchy (1990) found that outcome feedback but not process feedback after a stock-market simulation exercise enhanced participants' self-confidence. In mental-rotation tests, confidence after the solution of the items is higher in males than in females (Cooke-Simpson \& Voyer, 2007; Cross, Brown, Morgan, \& Laland, 2017). Furthermore, confidence predicted 
performance (Estes \& Felker, 2012) and males' confidence is more accurately related to their performance than females (Cooke-Simpson \& Voyer, 2007).

Cross et al. (2017) administered a mental-rotation test to participants, let them rate their confidence and provided them with answers of other participants as social information. This social information was real in some trials and manipulated in other trials and participants were informed about that. After the social information, subjects had the chance to change their initial answer. Males outperformed females in the mental-rotation task and reported higher confidence scores than females. Participants that were more confident were less likely to switch their initial answer and females changed their answers more often than males. Males and more confident subjects seemed to stick more likely to their initial answer regardless of the feedback from other participants (Cross et al., 2017).

In a mental-rotation study comparing participants with and without feedback, main effects of feedback condition for reaction time appeared only for females (Rahe, Ruthsatz, Schuermann, \& Quaiser-Pohl, 2019). Females but not males reacted faster in the condition with feedback than without feedback. For participants' confidence, males reported higher confidence scores than females but only in the condition without feedback. When participants got individual item-wise feedback, no gender differences in confidence appeared (Rahe et al., 2019).In a creativity task, gender differences in confidence did not disappear after positive or negative feedback (McCarty, 1986). Completing a mental-rotation test after manipulated confidence, Estes and Felker (2012) found main effects of gender and confidence but no interaction of both. Males outperformed females and more confident participants outperformed less confident subjects. Effect sizes for gender difference did not differ between both groups of more and less confident participants.

In the present study, varying effects of feedback on the mental-rotation performance of boys and girls will be analysed. We hypothesize that boys outperform girls in mental-rotation performance (Voyer et al., 1995). Participants in the feedback condition should be faster than in the condition without feedback (Starns \& Ratcliff, 2010). Gender differences will be analysed more closely for the feedback and the non-feedback condition. If gender differences appear in the non-feedback condition but not in the feedback condition, this could help to explain the smaller gender differences in chronometric mental-rotation tests compared to the paper-and pencil version (Voyer et al., 1995). Furthermore, effects of the feedback condition will be analysed for boys and girls separately. If girls perceive the feedback as an attempt to control them and therefore, do not benefit from the feedback (Katz et al., 2006), other task characteristics that vary between the two test versions should be responsible for the smaller gender differences in chronometric tests.

\section{METHODOLOGY}

\section{Participants}

Forty male and 59 female fourth-grade elementary school children participated in this study. Three children were identified as outliers for reaction time and one gave the same answer to all items. A subject was identified as an outlier if the absolute z-score was higher than 3.29 (Field, 2013). These four children were excluded from all further calculations. From the remaining 95 participants, no feedback was given to 19 males and 25 females while 20 males and 31 females solved the test in the condition with feedback. 
All parents and children gave their informed consent.

\section{Material}

A chronometric mental-rotation test with cube figures according to Shepard and Metzler (1971) with 32 practice items and 96 test items was administered to all participants. Two cube figures appeared on a computer screen for each item. The participants had to decide whether these two items were identical or mirrored versions of each other. The left object was presented upright and the right object was an identical or mirrored version and rotated in depth in angles of $0^{\circ}, 45^{\circ}, 90^{\circ}, 135^{\circ}$, or $180^{\circ}$ to the left or to the right. After giving the answer, feedback indicated whether the answer was right or wrong for all practice items and for the test items in the feedback condition. The feedback consisted of a green square in the right lower corner of the screen if the answer was correct and a red square in the same position if the answer was incorrect (Figure 1).
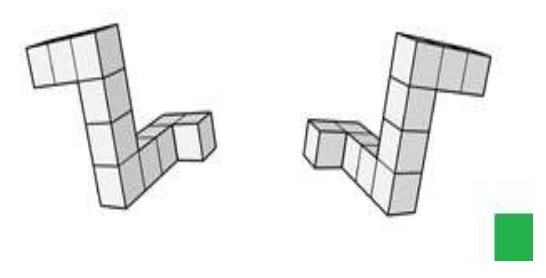

Figure 1. Example item of the chronometric mental-rotation test with positive feedback

\section{Procedure}

Participants were tested in a quiet room in their school in pairs of two. First, a detailed instruction was given to the subjects about how to rotate the objects and how to find identical and mirrored versions to make sure all children understood the task. Then the children were seated in front of the laptops and were instructed to solve the practice items as fast and accurately as possible. All participants got individual feedback after each item during practice. When there were no more questions about the task, the children solved the test items either with or without feedback.

\section{RESULTS}

For reaction time, main effects of condition $(t(93)=2.79, p=.006, d=0.579)$ and gender $(t(93)=$ $-2.34, p=.022, d=0.485$ ) were found (Figure 2). Boys reacted faster than girls and overall, children in the condition with feedback reacted faster than children who solved the test without feedback. For boys, there was a significant main effect of condition $(t(37)=2.66, p=.011, d=0.875)$; with feedback, boys reacted significantly faster than without feedback. For girls, no main effect of condition $(t(54)=1.67, p=.098, d=0.459)$ appeared. Gender differences in favor of boys appeared only in the feedback condition $(t(49)=-2.88, p=.006, d=0.813)$ but not without feedback $(t(42)$ $=-0.98, p=.332, d=0.303)$. 
Vol.8, Issue 4, pp.95-102, April 2020

Published by ECRTD- $U K$

Print ISSN: ISSN 2054-6351: Online ISSN: ISSN 2054-636X

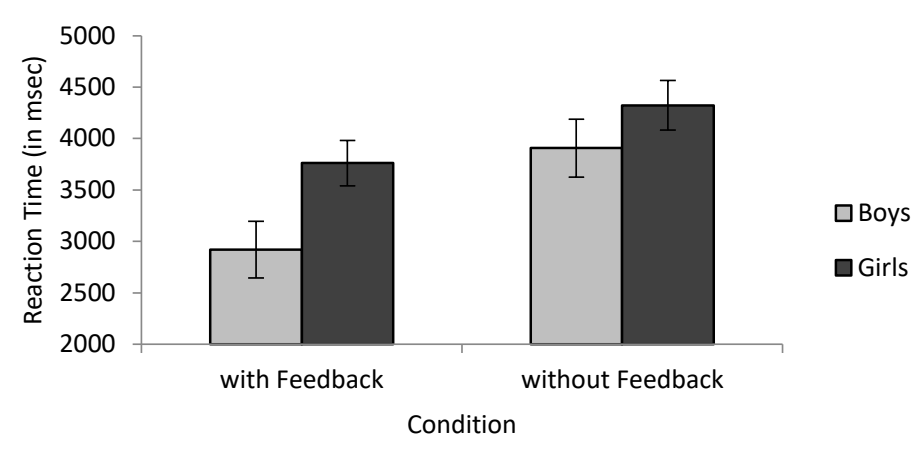

Figure 2. Reaction time dependent on gender and condition. Error bars indicate $S E$.

Because the distribution was right-skewed (skewness: 1.068, $S E=.247$ ), non-parametric tests (Mann-Whitney-U) were calculated for error rate. No significant main effects of gender $(U=$ $1119.00, z=0.201, p=.841, r=.021)$ or condition appeared for error rate $(U=1095.00, z=-0.205$, $p=.837, r=-.021)($ Table 1$)$.

Table 1. Error Rate for both conditions and genders.

\begin{tabular}{lll}
\hline & \multicolumn{2}{l}{ Error Rate (in \%) } \\
\hline & Girls & Boys \\
\hline With Feedback & $M d n=15.91$ & $M d n=14.38$ \\
Without & $M d n=15.22$ & $M d n=11.63$ \\
Feedback & & \\
\hline
\end{tabular}

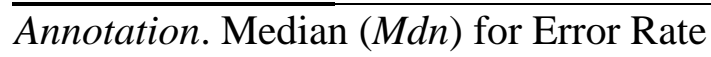

\section{DISCUSSION}

For reaction time, a gender difference favouring males was found. Boys reacted faster to the task than girls. However, boys did not outperform girls in error rate. Jansen, Schmelter, Quaiser-Pohl, Neuburger, and Heil (2013) found gender differences in error rate and reaction time favouring second and fourth-grade boys. In the present study, the distribution of the error rate was rightskewed. Therefore, a possible floor effect could be responsible for the absent gender differences.

Furthermore, children who got individual feedback after each item reacted faster than children in the condition without feedback. For error rate, no positive effect of feedback appeared. This is in line with results of Starns and Ratcliff (2010) who found that participants shifted their speedaccuracy balance to the speed side after they got feedback.

Analysing both genders separately, only boys benefitted from feedback in reaction time, while girls did not. If item-wise feedback in the chronometric mental-rotation test was partly responsible for smaller gender differences in this version of the test, girls should benefit more from feedback than boys. On the contrary, our results show that only boys seemed to use the feedback to react faster. A possible explanation could be that only boys gained confidence from the feedback during the experiment and reacted even faster than they did without feedback. Males usually report higher confidence levels in mental-rotation tests than females (Cooke-Simpson \& Voyer, 2007) and a study showed that participants with high confidence benefitted more from feedback than subjects with low confidence (Kulhavy et al., 1976). Combining both results, males should gain more from 
feedback than females, which would be in line with our results. On the contrary, Butler et al. (2008) suggested that participants with lower confidence would mostly benefit from feedback. Our results could not confirm these findings. A limitation of the present study is that we did not ask children about their confidence in their answer.

As boys did not outperform girls in error rate, maybe gender differences in confidence were not as pronounced as they are later in adulthood (Cooke-Simpson \& Voyer, 2007). Girls could have used a different strategy than boys (Heil \& Jansen-Osmann, 2008) and therefore might have been less influenced by feedback in reaction time and error rate. Previous research (Heil \& Jansen-Osmann, 2008) found that boys use the holistic strategy more often while girls rotate more analytical. If participants use the holistic strategy, they mentally rotate the figure as a whole. Using this strategy, it could be assumed that mental rotation can be improved in speed because of the feedback. If participants use the analytic strategy, they compare pieces of the object and mentally rotate these pieces. Maybe mental rotation could not be as easily improved when using the analytic strategy. It could be assumed that the time it takes to compare pieces of the objects could not be accelerated as easily as the time it takes to mentally rotate the whole object. Teaching especially girls to use the holistic strategy could enhance their performance due to faster reaction times.

Another explanation could be that girls were more cautious and took more time to answer regardless of feedback. This could also be due to a lower confidence of girls compared to boys (CookeSimpson \& Voyer, 2007). Hence, improving girls' confidence in their spatial abilities could also enhance their performance. Maybe the task was to short for girls to benefit from the feedback. Future research could investigate if girls would gain more from feedback with extended practice time.A previous study could show that for children with moderate interest, positive feedback resulted in less intrinsic motivation for girls and increased motivation for boys (Katz et al., 2006). The authors assumed that girls perceived the feedback as controlling. As mental rotation is a male stereotyped ability (Hirnstein, Andrews, \& Hausmann, 2014), girls could have feared to be compared with their male peers.

The effect of feedback is not always positive (Kluger \& DeNisi, 1996). The present study could show that in a mental-rotation test, only boys benefitted from individual item-wise feedback in reaction time. Therefore, feedback in school should be given with consideration of differences in children's personality, confidence, or assumptions of what the feedback really means. If the feedback is perceived as controlling, it could not reap its rewards (Katz et al., 2006). The same applies to children with low confidence in their performance (Kulhavy et al., 1976). Helping especially girls to gain more confidence in their spatial abilities could help them to increase their performance in spatial tasks. This could be done by less stereotyped education at home or in school so girls would not think that spatial tasks were activities where they were at a disadvantage compared to boys. Another possibility to strengthen girls' confidence in spatial tasks could be extracurricular lessons or tutorials teaching them in male-stereotyped activities, e.g. way finding, to make them more familiar with these tasks and therefore reduce their anxiety about such activities. It has also been shown that mental-rotation performance mediated the correlation of gender and math anxiety (Sokolowski, Hawes, \& Lyons, 2019). Improving girls' mental-rotation abilities could then also reduce their math anxiety. Future research could analyse the correlations between mental rotation and math anxiety considering feedback in both tasks. 
Vol.8, Issue 4, pp.95-102, April 2020

Published by ECRTD- UK

Print ISSN: ISSN 2054-6351: Online ISSN: ISSN 2054-636X

\section{CONCLUSION}

In conclusion, this research shed more light on the different effects of feedback on mental-rotation performance of boys and girls and therefore, could help to explain the varying gender differences in computerized and paper-and-pencil tests. It seems that feedback - as one possible attribute in which both test versions differ - is not responsible for smaller gender differences in chronometric tests.

\section{References}

Azevedo, R., \& Bernard, R. M. (1995). A meta-analysis of the effects of feedback in computerbased instruction. Journal of Educational Computing Research, 13(2), 111-127.

Bangert-Drowns, R. L., Kulik, C. L. C., Kulik, J. A., \& Morgan, M. (1991). The instructional effect of feedback in test-like events. Review of educational research, 61(2), 213-238.

Butler, A. C., Karpicke, J. D., \& Roediger III, H. L. (2008). Correcting a metacognitive error: feedback increases retention of low-confidence correct responses. Journal of Experimental Psychology: Learning, Memory, and Cognition, 34, 918.

Cooke-Simpson, A., \& Voyer, D. (2007). Confidence and gender differences on the Mental Rotations Test. Learning and Individual Differences, 17, 181-186.

Cross, C. P., Brown, G. R., Morgan, T. J., \& Laland, K. N. (2017). Sex differences in confidence influence patterns of conformity. British Journal of Psychology, 108(4), 655-667.

Earley, P. C., Northcraft, G. B., Lee, C., \& Lituchy, T. R. (1990). Impact of process and outcome feedback on the relation of goal setting to task performance. Academy of Management Journal, 33(1), 87-105.

Estes, Z., \& Felker, S. (2012). Confidence Mediates the Sex Difference in Mental Rotation Performance. Archives of sexual behavior, 41, 557-570.

Field, A. (2013). Discovering statistics using IBM SPSS statistics. Los Angeles: sage.

Hattie, J., \& Timperley, H. (2007). The power of feedback. Review of educational research, 77, 81112.

Heil, M., \& Jansen-Osmann, P. (2008). Sex differences in mental rotation with polygons of different complexity: Do men utilize holistic processes whereas women prefer piecemeal ones?. Quarterly Journal of Experimental Psychology, 61(5), 683-689.

Hirnstein, M., Andrews, L. C., \& Hausmann, M. (2014). Gender-stereotyping and cognitive sex differences in mixed-and same-sex groups. Archives of sexual behavior, 43(8), 1663-1673.

Jansen, P., Schmelter, A., Quaiser-Pohl, C., Neuburger, S., \& Heil, M. (2013). Mental rotation performance in primary school age children: Are there gender differences in chronometric tests?. Cognitive Development, 28(1), 51-62.

Katz, I., Assor, A., Kanat-Maymon, Y., \& Bereby-Meyer, Y. (2006). Interest as a motivational resource: Feedback and gender matter, but interest makes the difference. Social Psychology of Education, 9(1), 27-42.

Kluger, A. N., \& DeNisi, A. (1996). The effects of feedback interventions on performance: A historical review, a meta-analysis, and a preliminary feedback intervention theory. Psychological bulletin, 119, 254.

Kulhavy, R. W., Yekovich, F. R., \& Dyer, J. W. (1976). Feedback and Response Confidence. Journal of Educational Psychology, 68(5), 522.

Linn, M. C., \& Petersen, A. C. (1985). Emergence and characterization of sex differences in spatial ability: A meta-analysis. Child development, 1479-1498. 
Vol.8, Issue 4, pp.95-102, April 2020

Published by ECRTD- $U K$

Print ISSN: ISSN 2054-6351: Online ISSN: ISSN 2054-636X

McCarty, P. A. (1986). Effects of feedback on the self-confidence of men and women. Academy of Management Journal, 29(4), 840-847.

Peters, M. (2005). Sex differences and the factor of time in solving Vandenberg and Kuse mental rotation problems. Brain and cognition, 57, 176-184.

Quaiser-Pohl, C., Neuburger, S., Heil, M., Jansen, P., \& Schmelter, A. (2014). Is the male advantage in mental-rotation performance task independent? On the usability of chronometric tests and paper-and-pencil tests in children. International Journal of Testing, 14, 122-142.

Rahe, M., Ruthsatz, V., Schuermann, L., \& Quaiser-Pohl, C. (2019). The effects of feedback on the gender differences in the performance in a chronometric mental-rotation test. Journal of Cognitive Psychology, 31(4), 467-475.

Schunk, D. H., \& Lilly, M. W. (1984). Sex differences in self-efficacy and attributions: Influence of performance feedback. The Journal of Early Adolescence, 4(3), 203-213.

Shepard, R.N. \& Metzler, J. (1971). Mental Rotation of Three-Dimensional Objects. Science, 171, 701-703.

Sokolowski, H. M., Hawes, Z., \& Lyons, I. M. (2019). What explains sex differences in math anxiety? A closer look at the role of spatial processing. Cognition, 182, 193-212. doi.org/10.1016/j.cognition.2018.10.005

Starns, J. J., \& Ratcliff, R. (2010). The effects of aging on the speed-accuracy compromise: Boundary optimality in the diffusion model. Psychology and aging, 25, 377.

Van der Kleij, F. M., Feskens, R. C., \& Eggen, T. J. (2015). Effects of feedback in a computer-based learning environment on students' learning outcomes: A meta-analysis. Review of Educational Research, 85, 475-511.

Vandenberg, S.G. \& Kuse, A.R. (1978). Mental rotation, a group test of three-dimensional spatial visualization. Perceptual and Motor Skills, 47, 599-604.

Voyer, D. (2011). Time limits and gender differences on paper-and-pencil tests of mental rotation: a meta-analysis. Psychonomic bulletin \& review, 18(2), 267-277.

Voyer, D., Butler, T., Cordero, J., Brake, B., Silbersweig, D., Stern, E., \& Imperato-McGinley, J. (2006). The relation between computerized and paper-and-pencil mental rotation tasks: a validation study. Journal of Clinical and Experimental Neuropsychology, 28, 928-939.

Voyer, D., Voyer, S., \& Bryden, M.P. (1995). Magnitude of Sex Differences in Spatial Abilities. Psychological Bulletin, 117, 250-70. 